\title{
Dealing with Uncertainties in Fresh Water Supply: Experiences in the Netherlands
}

\author{
Wil Thissen ${ }^{1,7}$ - Jan Kwakkel ${ }^{1} \cdot$ Marjolein Mens $^{2,3}$ • \\ Jeroen van der Sluijs ${ }^{4,5} \cdot$ Sara Stemberger $^{4}$ • \\ Arjan Wardekker ${ }^{4}$ - Diana Wildschut ${ }^{4,6}$
}

Received: 30 September 2014 / Accepted: 19 November 2015 /

Published online: 23 December 2015

(C) The Author(s) 2015. This article is published with open access at Springerlink.com

\begin{abstract}
Developing fresh water supply strategies for the long term needs to take into account the fact that the future is deeply uncertain. Not only the extent of climate change and the extent and nature of its impacts are unknown, also socio-economic conditions may change in unpredictable ways, as well as social preferences. Often, it is not possible to find solid ground for estimating probabilities for the relevant range of imaginable possible future developments. Yet, some of these may have profound impacts and consequences for society which could be reduced by timely proactive adaptation. In response to these and similar challenges, various approaches, methods and techniques have been proposed and are being developed to specifically address long-term strategy development under so-called deep uncertainty. This paper, first, offers a brief overview of developments in the field of planning under (deep) uncertainty. Next, we illustrate application of three different approaches to fresh water provision planning under uncertainty in case studies in the Netherlands: a resilience approach, oriented to (re) designing fresh water systems in such a way that they will be less vulnerable, resp. will be able to recover easily from future disturbances; a robustness approach, oriented to
\end{abstract}

Wil Thissen

w.a.h.thissen@tudelft.nl

1 Faculty of Technology, Policy and Management, Delft University of Technology, Jaffalaan 5, 2628 BX Delft, The Netherlands

2 Department of Flood and Drought Risk Analysis, Deltares, P.O. Box 17, 2600 MH Delft, The Netherlands

3 Twente Water Centre, Twente University, P.O. Box 217, 7500 AE Enschede, The Netherlands

4 Centre for the Study of the Sciences and the Humanities and Department of Chemistry, University of Bergen, PO Box 7805, 5020 Bergen, Norway

5 Copernicus Institute of Sustainable Development, Utrecht University, PO Box 80115, 3508

TC Utrecht, Netherlands

6 Cooperative University of Amersfoort, Geldersestraat 6, 3812 PP Amersfoort, The Netherlands

7 UNESCO-IHE Institute for Water Education, Westvest 7, 2611 AX Delft, The Netherlands 
quantitative assessment of system performance for various system configurations (adaptation options) under a range of external disturbances, and an exploratory modeling approach, developed to explore policy effectiveness and system operation under a very wide set of assumptions about future conditions.

Keywords Fresh water supply $\cdot$ Uncertainties $\cdot$ Adaptation $\cdot$ Resilience $\cdot$ Robustness

\section{Uncertainties: New Challenges for Decision Making on Fresh Water Supply Systems}

Decision making and planning for fresh water supply are challenging because of a number of different reasons: First, a variety of individual measures or tactics need to be considered at both the supply and the demand side, including regulation, adaptation of infrastructure elements, subsidies or fines, operational control and coordination, etc., and appropriate combinations of these need to be made in the process of policy design. Second, different scales need to be considered, such as the local, regional, national and river basin scales, each having their associated governmental bodies. Third, a range of sometimes conflicting interests needs to be considered. Fourth, various uncertainties come into play. Traditionally, ample attention has been given to natural climate variability, for which empirical data are available and probabilistic approaches can be used to estimate the likelihood and consequences of various climate scenario's, and to assess the effectiveness of alternative policies. It has been argued that under the rapidly changing global climate, the assumption of stationarity is no longer valid, meaning that historic return frequencies of extreme hydrological and weather conditions can no longer be relied on in water management: here the past is no longer the key to the future (Milly et al. 2008). Long-term decision making, involving, for example, decisions regarding water supply infrastructures having long lifetimes, brings a new class of important uncertainties. Climate change, itself being uncertain, may have significant - yet uncertain - impacts on precipitation and evaporation patterns, salt intrusion, salinization, and seasonal variation. In addition, a variety of uncertain but possible developments in land use and agricultural conditions, food markets, spatial developments, economic developments, future technology, and future societal values may also affect the future impacts and valuation of policies that have to be decided in the short term.

Partly but not exclusively triggered by the need to explore the impacts of climate change, during the last decade, the literature on dealing with various sorts of uncertainties has been developing rapidly (e.g., Maxim and Van der Sluijs 2011; Van Bree and Van der Sluijs 2014). Therefore, in this paper, we will first give a brief overview of some of the major developments in the uncertainty literature. Next, three examples are presented of application of one of the many approaches under development in the field of fresh water supply. We conclude with a few general observations on the state of the art, and recommendations for further work in the field.

\section{Developments in Dealing with Uncertainties}

Knowledge available for long-term policy making is unavoidably incomplete and often controversial. In the science-policy interface, strategic use of uncertainties seems to dominate: uncertainties are either downplayed to promote political decisions or they are overemphasized to prevent political action. Both are problematic and lead to policy strategies that are not fit for 
meeting the challenges posed by the uncertainties and complexities faced. While the scientific community has not ignored the problems of uncertainty, most efforts thus far have been associated with analysing and dealing with those uncertainties that can be described quantitatively (e.g., probabilistically, like in risk analysis), and with efforts at reducing uncertainties through additional research and/or refined modelling.

Not all uncertainties encountered in decision making can be quantified. In fact, unquantifiable uncertainties can sometimes be more relevant than the part where we do have enough knowledge to quantify uncertainty. Rather than using such unquantifiable uncertainties in a strategic way, or ignoring them, there is a growing consensus among scholars that deliberate policy strategies in the face of often irreducible uncertainties should be developed and implemented (Van der Sluijs et al 2008), and a wide variety of approaches and methods have emerged in the literature on the subject. As a result, the field is quite fragmented, and different key authors and groups have developed their own terminologies. A certain degree of conceptual confusion results, as approaches partially overlap, and different authors use the same terms in different ways. For example, approaches like 'Adaptive Management', 'Adaptation Policy Framework', and 'Robust Decision making' strongly (but not completely) overlap in their guiding principles.

Despite the fragmented character of the field, there seems to be a general agreement that different approaches are suitable under different degrees and types of uncertainty, that in real world situations often different types of uncertainty are present at the same time, and that combinations of approaches need to be fine-tuned to the characteristics of the situation. We will now briefly elaborate on these aspects.

\subsection{Types and Levels of Uncertainty}

In an attempt to harmonize diverse literatures in as far as they relate to model-based decision support, Walker et al. (2003) presented an uncertainty framework. The starting point for this framework is the distinction between an analyst's perspective on uncertainty and a decision maker's perspective on uncertainty (van Asselt 2000). The framework focuses on the analyst's perspective on uncertainty. A central idea of this framework is that uncertainty is a multidimensional concept. Ironically, this framework in turn had its own variants, motivated by various perceived shortcomings of the original typology or perceived need to tailor it to a specific field of study. More recently, Kwakkel et al. (2011) presented a review of the variants and what motivated them, and presented a new framework that integrated and harmonized the variants. Both the original and the new framework categorize uncertainties by their location, nature, and level. The location dimension focuses on where the uncertainty is located. The nature dimension focuses on the character of the uncertainty, i.e., whether the uncertainty is knowledge-based, a direct consequence of inherent variability, or related to human interpretation (ambiguity) or human values now and in the future. The level dimension focuses on the severity of the uncertainty.

Each of the three dimensions is relevant when selecting an appropriate approach for handling the uncertainty. However, the level dimension plays the most important role. Broadly speaking, the level of uncertainty is the assignment of likelihood to things or events. In some cases the likelihood or plausibility of these things, events or situations can be expressed using numbers, but in other cases more imprecise labels are used, such as more likely, less likely, or equally likely. Overall, the level of uncertainty ranges from complete certainty to absolute ignorance. We define five intermediate levels of uncertainty: we speak of 
level 1 uncertainty, or recognized uncertainty, when one admits that one is not absolutely certain but when one is not willing to measure the degree of uncertainty in any explicit way (Hillier and Lieberman 2001). We speak of Level 2 uncertainty, or shallow uncertainty, when one is able to enumerate multiple possibilities and is able to provide probabilities. We speak of Level 3 uncertainty, or medium uncertainty, when one is able to enumerate multiple possibilities and able to rank order them in terms of perceived likelihood. However, how much more likely or unlikely one possibility is compared to another cannot be specified. We speak of Level 4 uncertainty, or deep uncertainty, when one is able to enumerate multiple possibilities without being able or willing to rank order the possibilities in terms of how likely or plausible they are judged to be. Finally, we speak of Level 5 uncertainty, or recognized ignorance when one is unable to enumerate multiple possibilities, while admitting the possibility of being surprised (Kwakkel et al. 2011). Table 1 summarizes the five levels.

\subsection{A New Paradigm for Handling Uncertainty}

Uncertainties pose a significant challenge to planning and decision making. The dominant approach in many fields has been to ignore the uncertainties, to quantify them into error margins, to try and reduce them, or to deal with only those uncertainties that can be easily quantified (Quade 1982; Dempsey et al. 1997; Marchau et al. 2009; Van Geenhuizen et al. 2007; van Geenhuizen and Thissen 2007; McDaniel and Driebe 2005). However, such approaches suffer from the problem that they focus on those uncertainties that are "among the least of our worries; their effects are swamped by uncertainties about the state of the world and human factors for which we know absolutely nothing about probability distributions and

Table 1 The five levels of uncertainty (adapted from Kwakkel et al. 2010b)

Level of Uncertainty Description Examples

Level 1 (recognized Recognizing that one is not absolutely uncertainty) certain, without being able or willing to measure the uncertainty explicitly.

Level 2

(shallow uncertainty)

Level 3

(medium uncertainty)

Level 4

(deep uncertainty)

Level 5

(recognized ignorance)
Being able to enumerate multiple alternatives and being able to provide probabilities (subjective or objective)

Being able to enumerate multiple possibilities and being able to rank order the possibilities in terms of perceived likelihood. However, how much more likely or unlikely one alternative is compared to another cannot be specified

Being able to enumerate multiple possibilities without being able to rank order the possibilities in terms of how likely or plausible they are judged to be

Being unable to enumerate multiple possibilities, while admitting the possibility of being surprised
Performing a sensitivity analysis on a parameter in a model by changing its default value with some small fraction.

Being able to enumerate multiple possible futures or alternative model structures, and specify their probability of occurring

Being able to enumerate multiple possible futures or alternative model structures, and being able to judge them in terms of perceived likelihood

Being able to enumerate multiple possible futures or specify multiple alternative model structures, without being able to specify their likelihood

Keeping open the possibility of being wrong or being surprised 
little more about the possible outcomes" (Quade 1982). Similarly, Goodwin and Wright (2010) (p. 355) demonstrate that "all the extant forecasting methods - including the use of expert judgment, statistical forecasting, Delphi and prediction markets - contain fundamental weaknesses." And Popper et al. (2009) state that the traditional methods "all founder on the same shoals: an inability to grapple with the long-term's multiplicity of plausible futures." In response to this, various new planning approaches have been put forward (e.g., Lempert et al. 2003; Walker et al. 2001; de Neufville 2000, 2003; Dewar 2002; Dewar et al. 1993; Holling 1973; Lempert 2002). These approaches generally contain three types of elements:

- analytic methods and tools to capture and assess the (consequences of) uncertainties,

- $\quad$ specific action or policy strategies in light of irreducible uncertainties,

- $\quad$ specific, often participatory processes to involve stakeholders and decisionmakers

Analytic approaches (Swanson et al. 2010) generally emphasize the need for a more thorough integrated forward-looking analysis of the uncertainties through techniques such as exploratory modelling and analysis (Agusdinata 2008; Lempert et al. 2003), bounce casting (Kahan et al. 2004), and scenarios in various forms (Bradfield et al. 2005; Varum and Melo 2010).

The action or policy strategies can be divided in three partly overlapping categories: First, so-called top-down or robust strategies build on analytic approaches in order to assess the vulnerability of alternative strategies, and to select those policies that do well under a wide variety of possible futures. Second, so-called bottom-up, resilience-based strategies recognize the limited capability of analytic approaches for anticipating rare events, and focus on the system-to-be-governed or to-be-designed itself, and try to enhance the system's inherent ability to cope with disturbances and its self-organizational capacity in a comprehensive way (e.g., Wardekker et al. 2010). Third, there is a growing interest in flexibility and adaptability in plans in which a strategic vision of the future is combined with short-term actions and a framework that can guide future actions (Albrechts 2004; Walker et al. 2001; Walker et al. 2013).

Together with a focus on involving stakeholders and decisionmakers in both the identification of uncertainties and the assessment of alternative strategies, these new approaches can be considered to form a new emerging paradigm for handling uncertainty differently. They are based on accepting the uncertainties, and focusing on the question what can best be done now, given that we don't know what the future will bring.

For a more complete overview of concepts, approaches and methods, the reader is referred to recent review reports and articles (Dessai and Van der Sluijs 2007, 2011; Wardekker 2011; Walker et al 2013; Lourenço et al 2014a; van Bree and van der Sluijs 2014).

\subsection{Applications in the Field of Fresh Water Supply}

As explained above, fresh water supply planning faces a variety of uncertainties, part of which cannot adequately be dealt with in a (purely) probabilistic way. Recently, a number of example applications of the type of approaches mentioned above have been reported in the literature. For example, Groves, et al. $(2007 ; 2012)$ have reported on a number of studies on fresh water supply in California and Colorado River, using the so-called 'robust decisionmaking' approach that is strongly based on analytical and computational techniques. Matrosov et al (2013a; 2013b) apply among others Robust Decision Making to a fresh water supply case in the United Kingdom. Groot et al. (2014) report, among other things, on several practical cases of water supply planning in Portugal, the UK, and Hungary. These studies mostly were related to 
dealing with uncertainties of the scenario-type, and used a combination of multiple methods such as expert elicitation, stakeholder involvement and model-based sensitivity analysis. The studies demonstrate, on the one hand, the complexity of the challenge, and, on the other, the relevance of more explicitly dealing with uncertainties, and 'a shift towards a flexible, robust and no-regret approach' (Groot et al. 2014, p 67). Lourenço et al. (2014b) also emphasize a preference for 'options that contribute to enhance resilience and adaptive capacity'.

In another study in Hungary (Malatinszky et al. 2013), the focus was on climate adaptation strategies for wetlands and grasslands. The authors emphasize the importance and various benefits of stakeholder involvement in such processes, which include "enhanced awareness, willingness to taking action, inclusion of local knowledge, information exchange among affected parties, identification of win-win-solutions for land users and nature conservation, and building trust in authorities".

Clearly, while there seems to be agreement on the general tendencies of preferred approaches, much remains to be developed and learned, both with respect to methods and tools and their potential and limitations in practical applications and with respect to what strategies fit what uncertainty situations.

In the following sections, we will therefore, in order to learn more about their applicability, illustrate the application of three novel but different approaches to two different real-world fresh water supply cases in The Netherlands. First, the resilience approach is applied to an area of peat grassland in the west of the Netherlands. Second, a system robustness approach is applied to a low-lying polder area mainly used for agricultural purposes. Third, an exploratory modeling approach is applied to the same case study area.

\section{A Resilience Approach: the Venen-Vechtstreek Region}

\subsection{Resilience}

Resilience is a concept that emerged in ecology research in the 1960s. It was used in relation to the stability of ecosystems in the face of a wide range of external perturbations: "the amount of disturbance that a system can absorb and still remain within the same state or domain of attraction" (Holling 1973; Walker and Salt 2006). The concept has since been adopted by various disciplines, ranging from engineering to psychology, disaster studies, and climate change adaptation. Walker et al (2004) define resilience in relation to 'social-ecological systems' as: "the capacity of a system to absorb disturbance and reorganize while undergoing change so as to still retain essentially the same function, structure, identity, and feedbacks". Resilience focusses on coping with disturbances and preventing collapse into a qualitatively different state, rather than predicting and preventing disturbances.

In relation to climate change adaptation, resilience can be understood as a bottom-up approach, which aims at strengthening the system, removing vulnerabilities, and enhancing the capacity to cope with and recover from climate change-related disturbances and surprises. The case-study examined the consequences of various proposed measures and developments on the climate-resilience of the freshwater systems in the Venen-Vechtstreek region. These measures are plans to manage the area in general and are not specifically proposed to adapt to climate change.

Resilience analysis can take several steps. The first step is to determine 'resilience of what?'. This includes an overview of the area, the trends and challenges it faces, the way it is 
used, and the key characteristics and functions that make the system for what it is (i.e., if these are not retained, the system has shifted to a different state). The second step is to address the question of 'resilience to what?'. In this study, an inventory of climate change impacts was made. The third step is to assess the resilience of the system, measures that will enhance resilience, or the resilience consequences of developments. This case study concerned the latter. We applied a set of 'resilience principles' describing different mechanisms by which systems can absorb disturbances and retain identity (Watt and Craig 1986; Barnett 2001; Wardekker et al. 2010):

- Homeostasis: multiple feedback loops counteract disturbances and stabilize the system.

- Omnivory: vulnerability is reduced by diversification of resources and means.

- High flux: a fast rate of movement of resources (e.g., information, money, expertise, goods for emergency relief, fuel) through the system ensures fast mobilization of these resources to enable coping with perturbations through for instance reduced feedback delay. If information is proactively and rapidly exchanged, parties can act on this faster when there is a problem.

- Flatness: the hierarchical levels relative to the base should not be top-heavy. Overly hierarchical systems are too inflexible and too slow to cope with surprise. The more hierarchical levels exists through which stabilizing feedback signals must operate, the lower the signal to noise ratio and the lower the speed of signal transmission, and thus of action to counteract the perturbation or remedy the damage.

- Buffering: essential capacities are over-dimensioned such that critical thresholds are less likely to be crossed.

- Redundancy: overlapping functions; if one fails, others can take over.

\subsection{Case Study Area and Trends}

The Venen-Vechtstreek region is an area of peat grassland in the west of the Netherlands. It is known for its wide views, cow-filled meadows, and long and narrow stretches of land separated by water (Fig. 1). The appearance of the region has changed little over the centuries. The case study focused on the specific area of Groot Wilnis - Vinkeveen. The region is part of a range of wetlands forming a 'robust ecological corridor' between areas protected under Natura 2000, the European ecological network of protected areas. The corridor is intended to provide a connection and shelter that allows animals and plants to migrate between nature areas. The area is situated at approximately $2.5 \mathrm{~m}$ below sea level and is artificially drained.

Due to the artificial drainage, peat comes into contact with oxygen and decomposes. Consequently, the area suffers from soil subsidence. The most sensitive parts of the area have seen subsidence of up to $12 \mathrm{~mm}$ per year. Agricultural areas suffer more subsidence than nature areas, due to higher levels of drainage, resulting in large local differences in water levels. The decomposing peat also releases nutrients into the surface water and greenhouse gasses into the atmosphere.

The area is valuable for both ecological and agricultural reasons. The area's management covenant (Stichting Ontwikkeling De Venen 2010) specifies that the area should be preserved as an open landscape in which the dairy sector can continue to develop. Four key functions can be distinguished: fresh water supply, nature, agriculture, and recreation. Stakeholders aim to strengthen these functions, as well as to reduce the amount of soil subsidence. The functions 


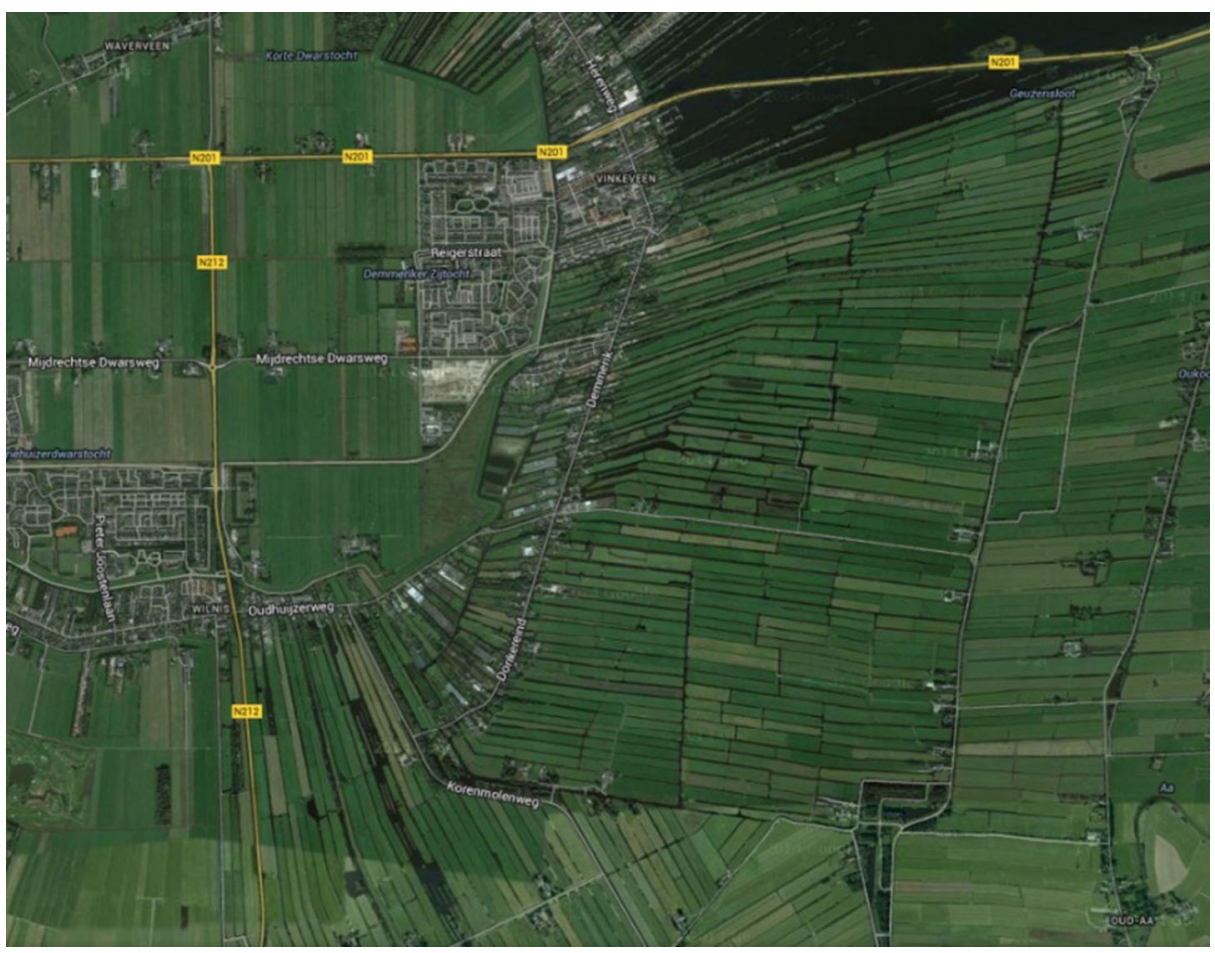

Fig. 1 Satellite view of the case-study area (source: Google Maps)

have different implications for the management of the area. Connecting them through integrated measures will be an important step in enhancing resilience.

Climate change will affect Dutch freshwater systems through increasing air and water temperatures, sea level rise, changes in seasonal river discharge, and changes in precipitation (PBL 2013). Average precipitation may either increase or decrease in summer, and increase in winter. For the study area, this may result in an increasing potential precipitation deficit during summer. Dry periods could negatively impact water availability and quality for fresh water supply as well as for nature and agriculture. Wet periods could result in flooding, negatively impacting all four functions. They could also exacerbate the current tension in water level requirements for agriculture (relatively low) and nature (relatively high), and enhance nutrient leaching from fields into surface water, negatively impacting nature. Temperature changes can impact various plants and animals. For 2050, a scenario study projects a moderate to high terrestrial drought risk, moderate risk of aquatic eutrophication, low risk of terrestrial eutrophication, and low to high risk of aquatic salinization (Verhoeven 2012). The high salinization risk occurred in a scenario with warm, dry summers, when brackish water from outside the area would be required to manage the water levels.

\subsection{Analysis}

A list was drafted including measures that are currently planned for managing the study area, based on the management covenant, other policy documents, and position papers of regional and national stakeholders. This list was supplemented with options that could contribute to the area's overall 
resilience. These supplementary options were collected through interviews with stakeholders and experts with experience concerning the study area. Options were categorized according to the key functions they contribute to: nature, agriculture, water quality, and recreation.

The research team performed an initial reflection on the resilience implications of the options, followed by a second set of interviews. These reflections were used in preparation of a workshop with stakeholders and experts on the area and on resilience: to select a subset of options to be discussed in the limited time available, and to seed the discussion. Workshop participants $(n=7$; this number is adequate for an expert assessment; $6-12$ is advisable, to cover relevant fields of expertise, but allowing for sufficient time for discussion; Knol et al. 2010) scored the shortlist of options on each of the resilience principles. They applied a fivepoint scale, ranging from strong decrease to strong increase of resilience. Aggregated 'resilience scores' were also generated. See Fig. 2.

Nearly all of the assessed options for nature improved resilience, according to the scores of most participants (occasionally, one or two participants disagreed). The participants expected the option 'marshland construction and capillarity' to perform particularly well. Agricultural options scored less well; half resulted in (slightly) reduced resilience. The option 'underwater drainage' did receive a good score. For both types of options, the range between individual aggregated scores was generally one to two points. Scores on separate resilience scores had similar ranges. They could on occasion diverge more strongly (up to scores of -2 to +2 , cf. Fig. 2, although these were exceptions), but the interquartile ranges (25-75 percentiles of scores) were two points in most cases. The group size was sufficiently large that a single expert scoring notably different did not change the interquartile ranges.

The approach to assessing resilience applied in this case study provided a useful tool to scan a variety of options on a range of impacts for a range of stakeholders on their implications. It allows

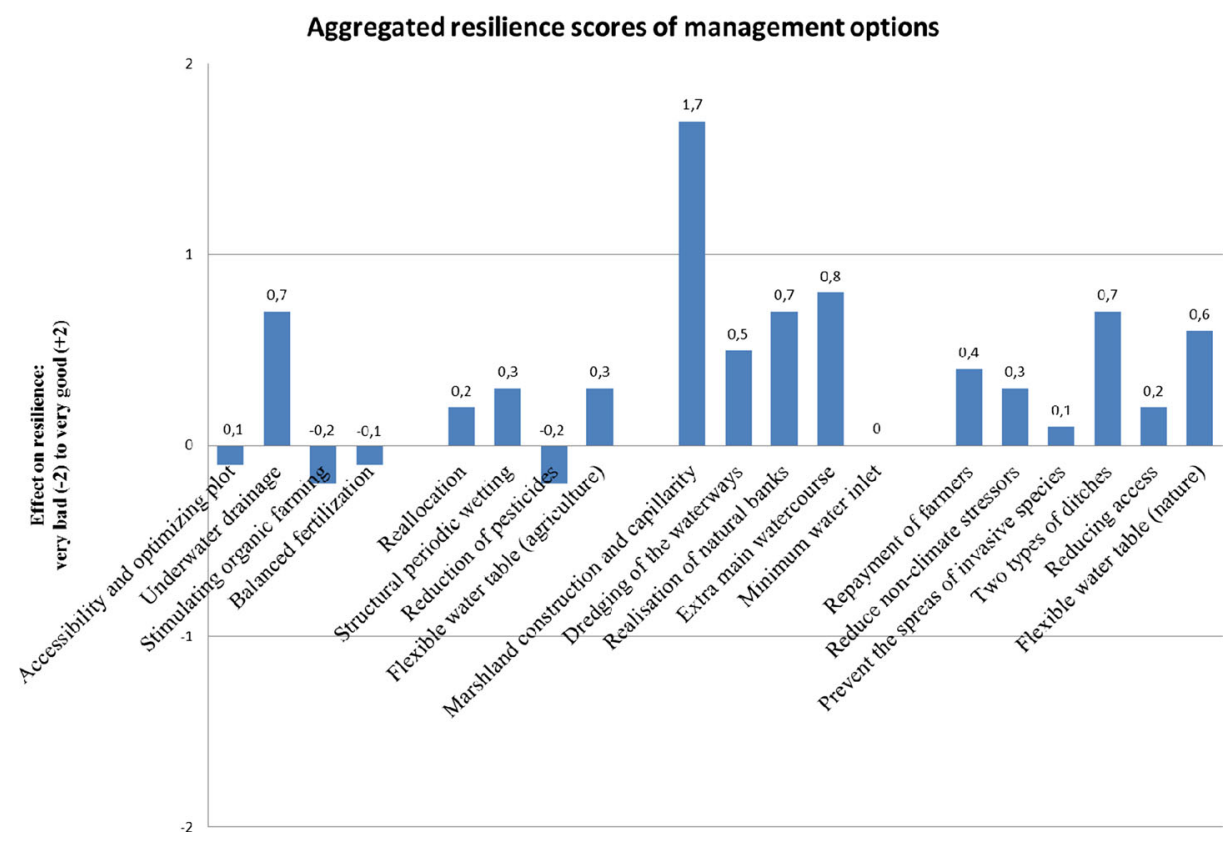

Fig. 2 Mean aggregated resilience scores. Options are arranged in four groups, from left to right: agriculture (planned and new) and nature (planned and new) 
for a relatively quick evaluation of options and the inclusion of stakeholders and their perspectives. The approach was also easy to combine with other decision criteria in a multicriteria assessment, allowing for a broader evaluation of policy options. Preferably, this would include multiple workshops with a broader range of expertise amongst the participants. A downside is that the assessment takes place on an ordinal scale (categories, rather than full quantification) and does not examine spatial patterns. Also differences in opinion between participants scores will remain, even with extensive discussion. These require further investigation and may hint at deeper differences in opinion (uncertainty due to ambiguity; see e.g., Brugnach et al. 2008), or different ways in which an option can be implemented. The approach can be applied for a broad range of cases, and does not require extensive computing power or special software. It does require some insight in the system dynamics of the case study (among researchers and participants), as well as experience with participatory processes (among researchers). It is possible to scan a broader set of options with the research team only, and/or include a larger set of stakeholders by means of a survey. However, discussion with, and among, local stakeholders and experts remains important to analyze local resilience in a meaningful way.

We concluded that, considering that agriculture is a key function of the area, covering most of the land use, it would be advisable to pay attention to increasing resilience in agricultural developments. Scores on separate resilience principles (i.e., not aggregated into a single resilience score) showed that very few options increase flatness. Additionally, few agricultural options address redundancy.

\section{A System Robustness Analysis: Case Rijnland}

\subsection{System Robustness}

System robustness is a concept that originates from engineering and biology, where it refers to the ability of systems to maintain system characteristics when subjected to disturbances (Carlson and Doyle 2002; Stelling et al. 2004). For example, a road network is robust to incidents when the effect on traffic congestion is prevented and/or limited (Snelder et al. 2012). According to the Merriam-Webster dictionary, the term robustness indicates that systems or networks are capable of performing without failure under a wide range of conditions. In the context of flood and drought risk management, system robustness is defined as the ability of a socio-economic system to remain functioning under a range of disturbance magnitudes (Mens et al. 2011). The term disturbance refers to an external event resulting from climate variability, for example floods or droughts. The system for which robustness is assessed comprises biophysical as well as socioeconomic aspects. For example, the robustness of a flood risk system does not only depend on the flood protection system, but also on the characteristics that determine the flood impact, and on the social and economic capacity to recover from these impacts. Failure of the system thus means that impacts are too large to recover from. Such impacts may be considered a catastrophe or a disaster. Likewise, a robust drought risk system is one that can resist frequent droughts (zero impact) and that can recover from socioeconomic impacts of rare droughts (limited impact).

System robustness can be assessed by studying the so-called response curve: the relationship between disturbance and response, for example the relationship between precipitation deficit and crop yield deficit. Key aspects of the response curve for this application are: 
- Resistance threshold: the smallest deficit causing yield deficit;

- Manageability: the severity of the yield deficit in comparison with a recovery threshold (i.e., the societally unacceptable level of yield deficit).

Manageability refers to how severe the impacts of a drought can become. Whether a response is considered severe depends on the social and economic capacity to recover from the response to a disturbance (see De Bruijn 2004). This capacity can be quantified by a recovery threshold, indicating the level of response from which it will be very difficult to recover. For example, when economic impacts of flooding exceed $5 \%$ of the national GDP, it often means that aid is needed from other countries (5). Manageability indicates the extent to which the response stays far from the recovery threshold for the range of considered disturbance magnitudes.

\subsection{Case Rijnland}

Droughts occur as a natural temporary feature of the climate (AMS 2013), but it may have an effect on reservoir storage, groundwater resources and river discharges, thereby potentially causing socio-economic and environmental impacts. Climate change may cause a change in the frequency and severity of droughts. Many water resources studies focus on the impact of climate change on long-term average flows (Lehner et al. 2006), thereby analysing the average demand and supply balance in the long-term. However, even if water supply is sufficient to meet demand on average, droughts may cause a temporary shortage of water which may have far-reaching impacts on society. Insight is thus needed into the impact of potential drought events resulting from climate variability, now and in the future.

To understand how systems robustness analysis can aid in the management of drought risk systems, it was applied on a case: Rijnland polder areas (Mens and Klijn 2015; Mens et al. this issue). A drought risk system is a geographical area that depends on one or more water resource for several functions (e.g., drinking water supply, industry, nature and agriculture). Drought, in this case defined as a period of precipitation deficit (i.e., evapotranspiration is larger than precipitation), may cause water shortage with an impact on the area's functions. Precipitation deficit is thus considered the disturbance to the system.

The case study area, Rijnland, is a system of low-lying polders with agriculture (potatoes, horticulture, bulbs, flowers, dairy farming) as the main land use type. This is a mixture of rainfed and irrigated agriculture. The water supply and drainage system consists of ditches, canals, lakes, and pumps and sluices. In winter, there is an excess of water that is drained and pumped out, and in summer fresh water is let into the surface water system from a nearby river (see also Mens et al. this issue). The inlet water is used for water level control, flushing for water quality management and water supply (irrigation, drinking water, industry). Water level control guarantees the stability of canal embankments, and flushing reduces the salinity in the canals and ditches, caused by seepage of saline groundwater. During an average summer, the total external fresh water inlet amounts 40 to $6010^{6} \mathrm{~m}^{3}$. In a dry summer, this may increase to about $10010^{6} \mathrm{~m}^{3}$ (Rijnland 2009). The analysis focuses on the impact of drought on agriculture.

\subsection{Model}

Figure 3 presents an overview of the model structure. The water demand module generates water demands for irrigation and water level control in rural areas and is a simple two layer grid-based groundwater model with a resolution of 250 by $250 \mathrm{~m}$, taking into account a limited number of 
Fig. 3 Diagram showing the basic structure of the model (adapted from Haasnoot et al. (2014))

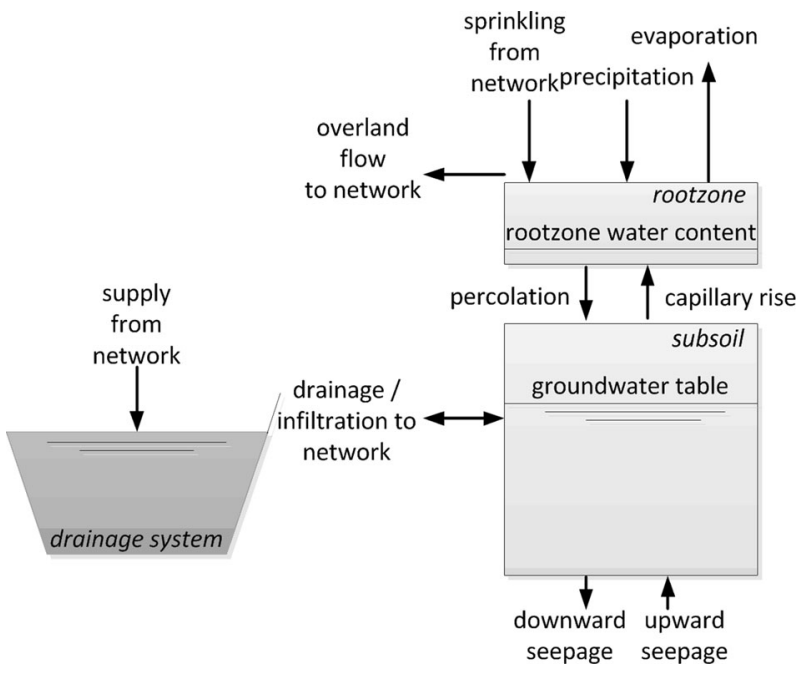

land use and soil types. For each layer in each grid cell, the model calculates the water balance. First, the potential evaporation is calculated by multiplying the reference evaporation with a crop factor that is specified for each crop and 10-day period. The actual evaporation is a function of the potential evaporation, the moisture in the root zone, and the soil moisture suction ( $\mathrm{pF}$ value). Lateral flow from groundwater to local surface water and vice versa is a function of groundwater depth relative to surface water level. Water flowing from the root zone to the subsoil (percolation) depends on the root depth, porosity, and precipitation. Capillary rise (flow from subsoil to root zone) is calculated as a function of the groundwater depth below the surface level and the root zone suction (Kabat and Beekma 1994; Oosterbaan 2001). The lower boundary condition of each plot is an annual seepage flux taken from results of the complex model for an average year. In case the root zone and subsoil are saturated, excess water is moved through surface runoff. In urban areas surface runoff is a function of the net precipitation and a runoff co- efficient of 0.8 (Urbonas and Roesner 1993). The water demand is determined from the difference between the actual and potential evaporation. The amount of water requested for maintaining the target water level in the local surface waters areas is derived from the net precipitation and the surface area of these waters. The grid cells are aggregated over a watershed area (called district).

The salt intrusion module simulates the salt concentration at the Gouda inlet depending on river discharge and sea level. This module is based on empirical correlation between the Rhine discharge at Lobith and salt concentrations in the lower river reaches calculated using a 1D hydraulic model (SOBEK) (van den Boogaard and van Velzen 2012).

$$
\begin{aligned}
& \text { Salt }=1700+(90-1700) \times \frac{e^{\text {Fact }}}{1+e^{\text {Fact }}} \\
& \text { Fact }=\left(\frac{Q_{\text {lobith }}-600}{2.211}\right)^{0.309}
\end{aligned}
$$

where $Q_{\text {lobith }}$ is the discharge at Lobith in cubic meter per second and Salt is the salt concentration at the Gouda inlet in milligram per liter. As discussed in Haasnoot et al. (2014), this relation will slightly underestimate the frequency of closure at Gouda. 
The focus of this analysis is on the economic damages to agriculture due to drought. For this, we use Agricom (Mulder and Veldhuizen 2014) which is an agro-economic model to estimate agricultural yield losses due to water shortage, saline soil moisture and water excess. Drought is defined in terms of

$$
E_{\text {ratio }}=\frac{E T_{\text {act }}}{E T_{\text {pot }}}
$$

Where $E T_{a c t}$ is the actual evatranspiration and $E T_{p o t}$ is the potential evapotranspiration. Given $E_{\text {ratio }}$ and crop specific damage curves that take into account the growing season, the $E_{\text {ratio }}$ is translated into a loss of yield in kilogram, which in turn is monetized. In our analysis, we calculate both the potential yield in Euro, assuming perfect conditions, and the actual yield in Euro's, allowing us to calculate the relative loss due to deficiencies in the system.

\subsection{Results}

The response curve of the reference situation is given in Fig. 4. Each point in the curve is a sample from climate variability according the current climate and according to the worst-case climate change scenario for 2100 . Together they provide an indication of the range of drought magnitudes that may occur and the corresponding impact on agricultural yield deficit. The vertical range is explained by the timing of the precipitation deficit within the growing season. Some crops are more sensitive to drought in the beginning of the season, while others are more sensitive at the end of the season. Droughts with similar precipitation deficits may therefore occur, but when they differ in timing the impact will differ as well.

There are two lines drawn in the figure: one at $5 \%$ yield deficit and one at $10 \%$ yield deficit. Yield deficits below $5 \%$ are considered not significant, because farmers take into account some level of business risk. The first point that exceeds this line (indicated with an arrow) indicates the resistance threshold at $250 \mathrm{~mm}$ precipitation deficit. The $10 \%$ line is arbitrarily chosen to indicate the level of unacceptable yield deficit that must be avoided (recovery threshold). Only two of the 35 events exceed this $10 \%$ line in the future climate.

Fig. 4 Response curve of the Rijnland system: yield deficit as a function of maximum cumulative precipitation deficit (MCPD), the indicator for drought magnitude

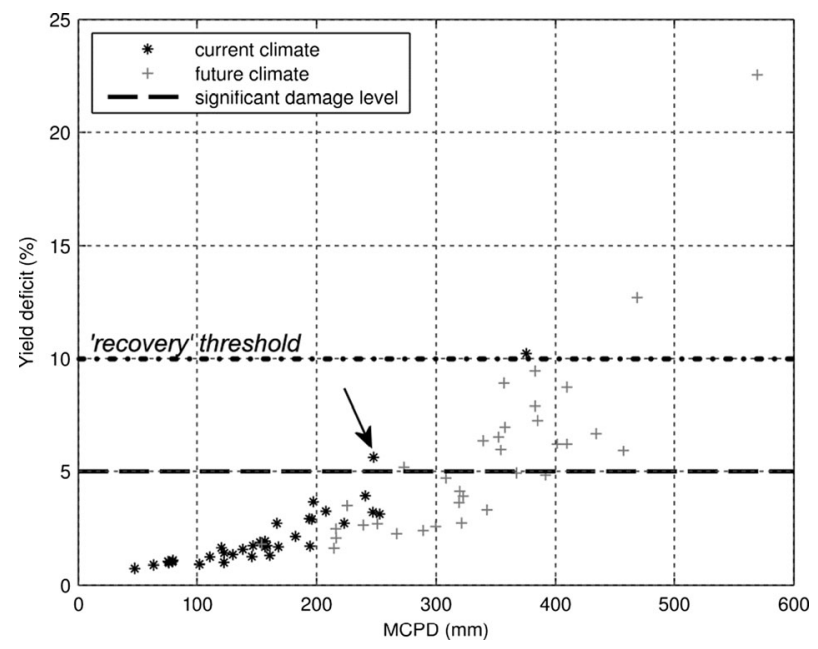


When it is aimed to enhance the manageability, measures should be designed that reduce the impact for these events.

In practice, the location of both the $5 \%$ and the $10 \%$ line is a political choice. In fact, the real recovery threshold in this system will never be exceeded, since it can be expected that the area can still economically recover from $100 \%$ yield deficit (see Mens et al. this issue). The Rijnland system can be considered robust to droughts, because the maximum simulated yield deficit does not exceed $25 \%$ for a large range of precipitation deficits. This can be partly explained by the storage capacity as well as the diversity of crop types that vary in when they are most sensitive to water shortage (Mens et al. this issue).

\subsection{Reflection}

Although the model obviously is a limited representation of reality, it suffices for the purpose of the robustness analysis. Different model parameter assumptions could slightly change the resistance threshold, but the score on proportionality and manageability is not expected to change. Thus, the conclusion on how well the system is able to deal with a range of drought events is not affected by the choice of the model.

Two types of measures are often considered in a drought risk context: those that increase the water supply and those that reduce the water demand. In traditional decision making approaches, where supply reliability is the main decision criterion, both types of measures will increase the supply reliability. However, a high reliability does not inform about the consequences of low-probability drought events. Additional criteria are thus needed that assess measures on how they affect the system in terms of avoiding large societal and economic impacts due to droughts. The two robustness criteria, resistance threshold and manageability, seem to fulfil this need. More applications are needed to explore how different types of drought risk reduction measures score on the robustness criteria.

We believe that a robust system, that can deal well with frequent as well as rare events, will also be able to deal well with changed variability under a future climate (Watts et al. 2012). Knowledge or assumptions about the future climate variability are not needed to perform robustness analysis. However, climate change scenarios are helpful in determining the range of drought events for which the system's robustness is assessed.

\section{An Exploratory Modeling Approach for Designing Adaptation Pathways}

\subsection{Adaptation Pathways}

An emerging approach to the design of climate adaptation plans and strategies is adaptation pathways (Haasnoot et al. 2013; Wise et al. 2014). This approach combines two bodies of literature on planning under uncertainty: work on adaptive policymaking (Walker et al. 2001; Kwakkel et al. 2010; Hamarat et al. 2013) and work on adaptation tipping points and policy pathways (Kwadijk et al. 2010; Haasnoot et al. 2012; Offermans 2012). A plan is conceptualized as a series of actions taken over time. In order to come to a good plan, it is necessary to first identify candidate policy actions and their adaptation tipping points. An adaptation tipping point is the condition under which a given policy action no longer meets its objectives. The point in time at which this happens (the so-called sell-by-date) is scenario dependent. In light of an analysis of the sell-by dates of various policy actions, concatenations of options, or policy pathways, can be specified where a new policy option is activated once its predecessor 
is no longer able to meet the definition of success. Typically, there is a portfolio of pathways that decision-makers would like to keep open for the future. This adaptation map forms the basis for the plan. Figure 5 shows an example of such a map. For a more detailed elaboration on DAPP, see Haasnoot et al. (2013).

Model-based decision support for the design of adaptation pathways is challenging for a variety of reasons. There exist a wide variety of candidate policies that has to be considered. These policies might be sequenced in different ways, taking into account co-dependencies between the various options. Their assessment needs to explicitly take into account the dynamics over time, rather than some endpoint. The assessment also should cover the variety of outcomes of interest the different stakeholders involved in the decision-making care about. And last but not least, the assessment should cover the variety of irreducible uncertainties that exist and the performance of candidate pathways needs to be assessed over the full range of uncertain factors.

One approach that might be amendable to supporting the design of adaptation pathways is exploratory modeling. Weaver et al. (2013) have argued that adaptive planning requires an exploratory modeling approach. In exploratory modeling, modelers account for the various unresolvable uncertain factors by conducting series of computational experiments that systematically explore the consequences of alternative realizations of the various uncertain factors (Bankes et al. 2013). These computational experiments can be used also a test bed for candidate policies (Lempert et al. 2003).

\subsection{The Case, the Model and the Associated Uncertain Factors}

As case, we use the Rijnland case as described in section 4. We use the same model as used there with a few small changes. First, we adapted the model to account for the following uncertain factors:

- River runoff in the Rhine

- Rainfall

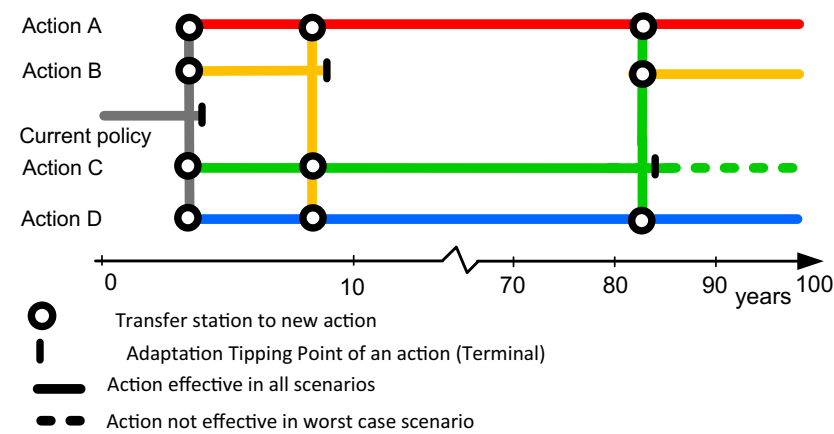

Adaptation Pathways Map

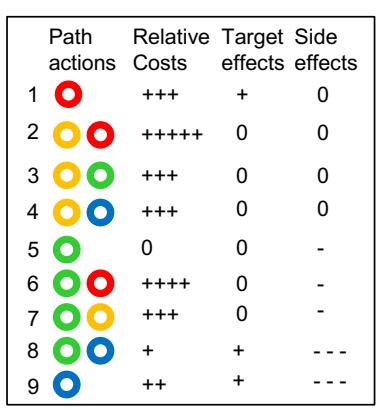

Scorecard for pathways

Fig. 5 An example of an Adaptation Pathways map (left) and a scorecard presenting the costs and benefits of the 9 possible pathways presented in the map. In the map, starting from the current situation, targets begin to be missed after 4 years. Following the grey lines of the current plan, one can see that there are four options. Actions $\mathrm{A}$ and $\mathrm{D}$ should be able to achieve the targets for the next 100 years in all climate scenarios. If Action $\mathrm{B}$ is chosen after the first 4 years, a tipping point is reached within about 5 years; a shift to one of the other three actions will then be needed to achieve the targets (follow the orange lines). If Action $\mathrm{C}$ is chosen after the first 4 years, a shift to Action A, B, or D will be needed after approximately 85 years in the worst case scenario (follow the solid green lines). In all other scenarios, the targets will be achieved for the next 100 years (the dashed green line). The colors in the scorecard refer to the actions: A (red), B (orange), C (green), and D (blue) 
- Land use

- Evatranspiration

For each of these sources of uncertainty we use transient scenarios (Haasnoot et al. 2014) to address them. So, rather than looking at the system in e.g., 2050, we consider the change over time from the current system to the state of the system in 2100 . For river runoff, rainfall, and evapotranspiration we use different possible realizations of the climate scenarios W+ and G.. These are climate scnearios for the Netherlands and have been developed by the Dutch Royal metrological institute. $\mathrm{W}+$ is an extreme warming scenario, while $\mathrm{G}$ represents a modest warming scenario (KNMI 2006). These realizations are the same as those used by Haasnoot et al. (2014), although here we only use the parts relevant to the case study area. We use 10 possible realizations of both scenarios. For land use, we use the land use as described in the four delta scenarios as developed in the Deltaprogram. These scenarios are labelled Warm, Pressure, Rest, and Steam. These delta scenarios combine the $2006 \mathrm{~W}+$ and G climate scenarios (KNMI 2006) with socio-economic scenarios. Figure 6 shows the scenario logic for the scenarios. Maps were available for 2050 and 2100. We interpolated the maps in between. Given that we sum up over the region, a rather simple and crude interpolation has been used. Combining the different realizations with he delta scenarios gives 40 scenarios. To assess the role of changing land use, we include, in addition to the changing land use also a no change case, giving 60 scenarios in total (i.e., Warm, Pressure, Rest, Steam, No change W+, and no change G). Note that in the current results land use has some influence on water demand, but the irrigation maps do not evolve with land use.

\subsection{Results}

A variety of analyses have been carried out. As a first experiment, we explore how the system responds if water supply is deliberately closed. To this end we simulate two situations. In the first situation, we keep the water inlet at Gouda open at all time, in the other, we close the inlet at all times. We assessed the performance for both situations by analyzing the results for 5000 experiments. A boxplot for the loss of income of farmers due to reduced yields in both situations is shown in Fig. 7. So, this is the monetized loss of yield as explained near the end of section 4.3. As can be seen, there are a few more extreme cases in terms of income loss when

Fig. 6 The scenario logic of the delta scenarios (adapted from (Delta Programme 2012) socio-economic growth

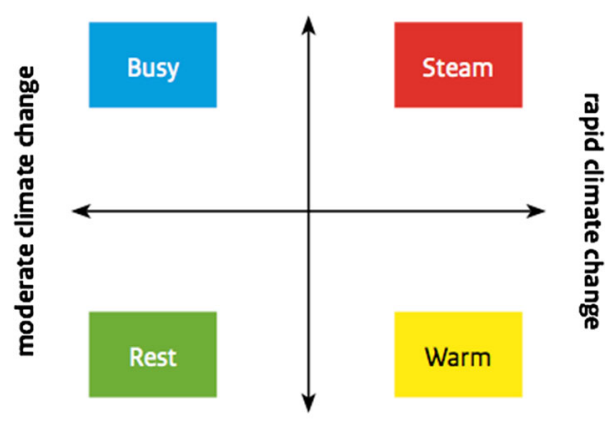

socio-economic squeeze 


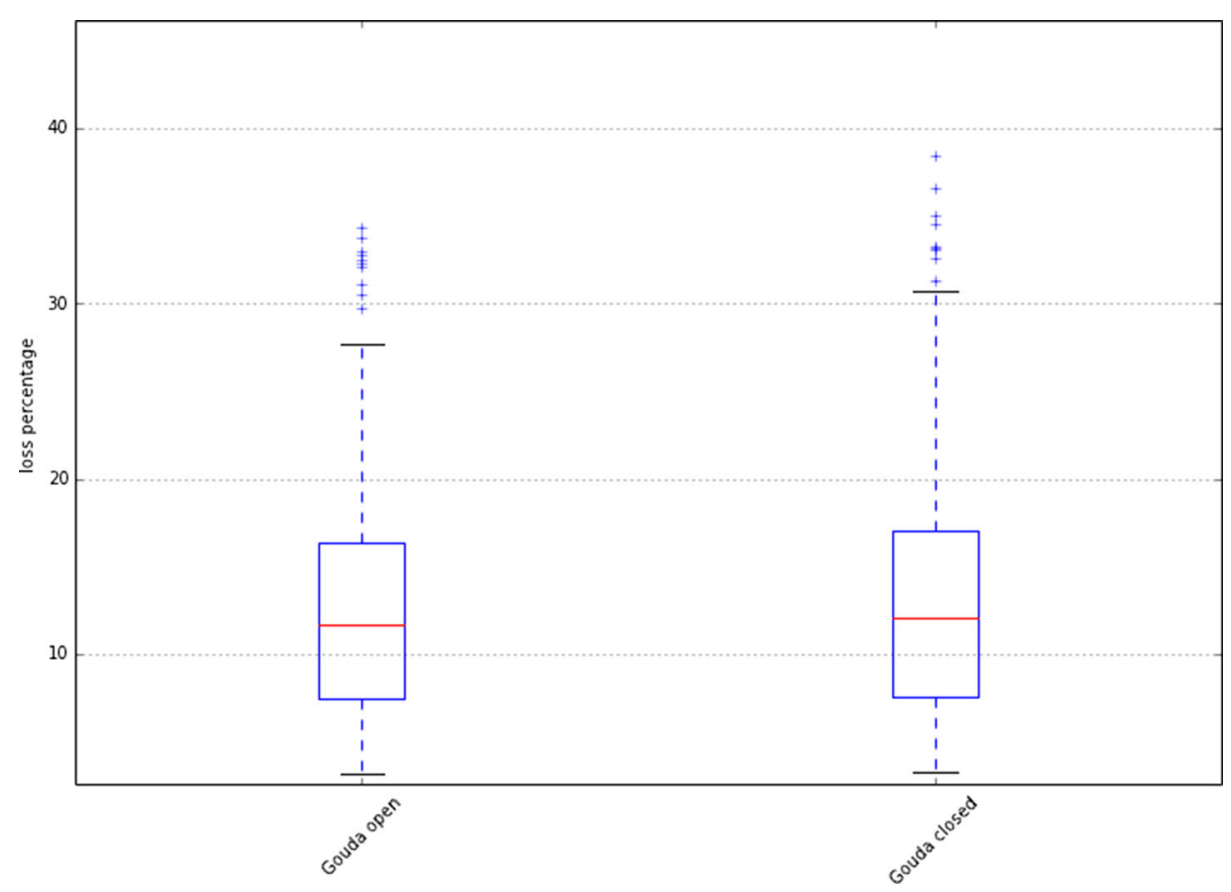

Fig. 7 Boxplot of percentage income loss for farmers due to a reduction in yields, comparing the situation where the fresh water inlet at Gouda is open at all times with the situation where the fresh water inlet at Gouda is closed at all times

the Gouda inlet is closed at all times. Still, the differences are quite small and it is relevant to investigate this further.

In order to understand why there is only a minor difference in income loss between the situation where the fresh water inlet at Gouda is always open, and the situation where the fresh water inlet at Gouda is always closed, we looked at the worst-case delta scenario. In this scenario, warm, the system experiences severe climate change, combined with substantial land use developments putting even more pressure on the system. We explored the behavior of the system for all ten possible realizations. The resulting water demands per decade are shown in Fig. 8.

In Fig. 8 we compare the water demand at a decade level for only those situations where Gouda is closed on the one hand, and for all decades on the other. As can be seen, during the decades during which the fresh water inlet at Gouda is closed, the water demand is quite small. In fact, the demand is below the supply available via the small scale water supply ( 5 cubic meter per second). As such, no severe water shortages occur. This suggests that decades with high demand for fresh water do not coincide with low runoff off of the Rhine. In light of this analysis, it appears that no future adaptation actions are necessary. There are a few caveats with this conclusion.

First, the relation used to calculate closure of Gouda is known to underestimate closures (Haasnoot et al. 2014). As such, a closer analysis on a different time scale might be needed. The current analysis uses decades, and it might be necessary to shift to a daily analysis to get a better insight into what is happening.

Second, the model does consider land use change. This land use change affects water demand. We have not translated the changes in land use into changes in the areas being irrigated. Doing so is possible. Ter Maat et al (2013), for example, introduce several additional assumptions regarding future irrigation demands, allowing the translation of land use change into changes in water demand. 


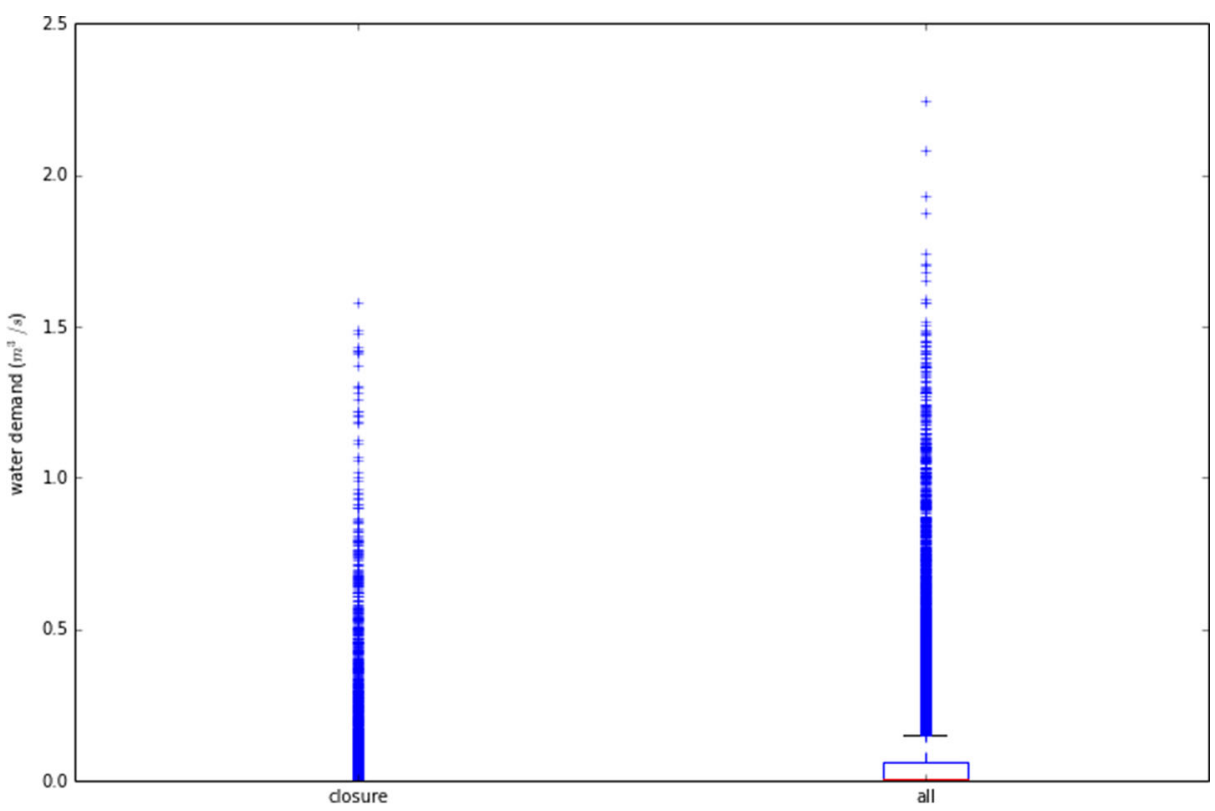

Fig. 8 Water demand per decade for the Warm scenario. The left hand boxplot contains the water demand when the fresh water inlet at Gouda is closed because of salt intrusion. The right hand boxplot contains all the decades irrespective of whether the fresh water inlet at Gouda is closed or not

We speculate that one of the reasons for the differences between the results reported here and those reported in ter Maat et al. (2013) are due to how changes in land use affect irrigation.

Third, it appears that the model at every time step resets the water levels to the norm height. Inspection of the source code of the model did not provide clarity as to where the water for this comes from. That is to say, it appears that a hidden assumption in the model is that that the full capacity of the KWA is available for maintaining water levels. Based on ter Maat et al. (2013), this assumption is questionable. If the model were modified such that the KWA is first used to maintain water levels, and only subsequently if possible for irrigation, it is plausible that there would be more severe fresh water shortages for irrigation. In turn, this would increase the income loss of farmers.

From a methodological point of view, the main conclusions of the analyses reported on are that it is possible to consider a wide range of different uncertainties simultaneously. Exploratory modeling offers an approach for systematically mapping out the consequences of various uncertainties. We also demonstrated that it is possible to do a variety of potentially useful further analyses on the exploratory modeling results. On the one hand, these analyses provide usefull information for policy-making. On the other hand, the analyses create new insight into the behavior of the models. Moreover, these kinds of analyses can also help in assessing the usefulness of models, since they stress test the model and clarify the domain over which the model provides meaningful results.

\section{Conclusions and Discussion}

Long term planning for fresh water supply faces a variety of sources and types of uncertainty, many of which cannot be adequately dealt with using probabilistic approaches. In response, a 
variety of complementary approaches has been proposed and developed to explicitly recognize and deal with these uncertainties. On the one hand, analytical methods are being developed to capture and assess uncertainties and their impacts, on the other, various action strategies are proposed in view of uncertainties, including approaches based on robustness, on resilience, and on flexibility and adaptation. We have illustrated the application of respectively a resilience approach, a robustness approach, and an exploratory modeling approach. Reflecting on these different approaches, we observe that the robustness approach requires quantification of uncertainties and computational analysis. The exploratory modeling approach builds on computational power and enables exploration of a broad set of possible assumptions about the future while relaxing requirements of probabilistic specification.

The resilience approach, on the other hand, is primarily qualitative. As a result, the effectiveness and efficiency of resilience options is difficult to assess in quantitative terms. But the resilience approach may, as illustrated, be more suitable for tailoring adaptation to local situations, and appeal to notions of stakeholder involvement and ownership, self-governance and self-relience. In contrast to the robustness and exploratory modelling approach, the resilience approach can be used for those adaptation policy challenges where the state of scientific knowledge does not (yet) allow a sufficiently adequate form of quantification of impacts at the spatial and temporal scales that are pertinent to that particular adaptation policy challenge.

Application in the Venen-Vechtstreek case illustrates that the resilience approach enables involvement of multiple stakeholder perspectives and consideration of multiple societal reactions (that in turn can influence the effectiveness of the various management options) as well as a range of other criteria relevant to the decision making challenge such as costs and cobenefits of the management options. In our workshop, the co-benefits turned out to be crucial to obtain support for resilience-based climate adaptation measures from local stakeholders such as farmers. The approach is especially useful for a quick screening of management options.

The robustness approach focusses on a partial challenge around a single metric (vulnerability of the present fresh water system from the view point of the water manager only), but enables spatially explicit detail and quantitative assessment of societal costs and benefits often required in policy making contexts to justify interventions that affect various stakeholders in various ways.

In practical terms, the resilience approach is useful in the phase where long term management and adaptation strategies for a region are being designed in multiple stakeholder processes and considering multiple impacts on multiple sectors. Robustness analysis is more useful to assess specific issues (vulnerability to a specific impact for a specific sector), and fit for situations where the relevant set of future scenario's is known and quantifiable. As such the approaches can be highly complementary (see also Wardekker et al. 2010). Especially in cases where decisions on dimensioning of options is key, a combination of approaches can have added value: if a resilience based screening of options reveals the wish to create fresh water buffers in an area (buffering) or to increase the inlet of fresh water from outside the area (ominvory), then a specific robustness analysis can help to answer the questions how big the buffer should be or what is the required capacity of the extra fresh water inlet should be.

More generally speaking, in practical cases different types of uncertainties will play a role, and analyses and strategies at different levels will be needed. As a result, a tailored combination of different approaches may be the best way forward, combining more top-down measures with bottom-up approaches. Clearly, both the analytical approach and the choice of strategies 
will have to be tuned to the characteristics of the situation, and more research and experience are needed to increase our understanding of the advantages and disadvantages for various approaches, and how they relate to the various types of uncertainties.

Another lesson from the cases presented here is that the match between the choice of policy objectives (which possible impacts do we seek to reduce with the adaptation policies) and the choice of scope and system boundaries of the scientific assessment carried out to support that decision making process is crucial. Is the key concern in agricultural impacts the physical yield (in kg of crops per ha) or the economic yield (in monetary units per ha)? Should we focus on the robustness of water supply only (how can we maintain the fresh supply under future climates to meet the given future demand) or should we address the robustness of the entire fresh water system? In the latter case, adaptation of water demand to a reduced supply would also need to be considered in the scientific assessment. This relates to the question whose perspective should guide the scientific assessment and who is and is not deemed responsible for adaptation.

Open Access This article is distributed under the terms of the Creative Commons Attribution 4.0 International License (http://creativecommons.org/licenses/by/4.0/), which permits unrestricted use, distribution, and reproduction in any medium, provided you give appropriate credit to the original author(s) and the source, provide a link to the Creative Commons license, and indicate if changes were made.

\section{References}

Agusdinata DB (2008) Exploratory modeling and analysis: a promising method to deal with deep uncertainty. Ph.D. thesis, Delft University of Technology

Albrechts L (2004) Strategic (spatial) planning reexamined. Environ Plann B 31:743-758

AMS (2013) Drought. An information statement of the American meteorological society. https://www.ametsoc. org/POLICY/2013drought_amsstatement.html. Accessed 29 September 2014

Bankes SC, Walker WE, Kwakkel JH (2013) Exploratory modeling and analysis. Encyclopedia of operations research and management science, 3rd edn. Springer, Berlin

Barnett J (2001) Adapting to climate change in Pacific Island Countries: the problem of uncertainty. World Dev 29:977-993

Bradfield R, Wright G, Burt G, Cairns G, Van Der Heijden K (2005) The origins and evolution of scenario techniques in long range business planning. Futures 37:795-812

Brugnach M, Dewulf A, Pahl-Wostl C, Taillieu T (2008) Toward a relational concept of uncertainty: about knowing too little, knowing too differently, and accepting not to know. Ecol Soc 13(2):30

Carlson JM, Doyle J (2002) Complexity and robustness. Proc Natl Acad Sci 99:2538-2545. doi:10.1073/pnas. 012582499

De Bruijn K (2004) Resilience indicators for flood risk management systems of lowland rivers. Int J River Basin Manag 2:199-210

De Neufville R (2000) Dynamic strategic planning for technology policy. Int J Technol Manag 19:225-245

De Neufville R (2003) Real options: dealing with uncertainty in systems planning and design. Integr Assess 4:26-34

Delta Programme (2012) Delta Programme 2013: the road towards the Delta Decisions, Dutch Ministry of Infrastructure and the Environment and the Ministry of Economic Affairs, Agriculture and Innovation

Dempsey PS, Goetz AR, Szyliowicz JS (1997) Denver international airport: lessons learned. McGraw-Hill, New York

Dessai S, Van der Sluijs JP (2007) Uncertainty and climate change adaptation - a scoping study. Copernicus Institute, Utrecht University, Utrecht

Dessai S, Van der Sluijs JP (2011) Modelling climate change impacts for adaptation assessments. In: Senn S, Dawid P, Christie M, Cliffen KA (eds) Simplicity, complexity and modelling. Wiley, Chichester, pp 83-102

Dewar JA (2002) Assumption-based planning: a tool for reducing avoidable surprises. Cambridge University Press, Cambridge

Dewar JA, Builder CH, Hix WM, Levin MH (1993) Assumption-based planning: a planning tool for very uncertain times. RAND Corporation, Santa Monica 
Goodwin P, Wright G (2010) The limits of forecasting methods in anticipating rare events. Technol Forecast Soc Chang 77:355-368

Groot A, Rovisco A, Capela LT (2014) Showcasing practitioners’ experiences. In: Lourenço TC, Rovisco A, Groot A, Nilsson C, Fussel HM, van Bree L, Street RB (eds) Adapting to an uncertain climate: lessons from practice. Springer, Berlin, pp 67-137

Groves DG, Lempert RJ (2007) A new analytic method for finding policy-relevant scenarios. Glob Environ Chang 17:73-85

Groves DG, Fischbach JR, Bloom E, Knopman D, Keefe R (2012) Adapting to a changing Colorado River: making future water deliveries more reliable through robust management strategies. RAND corporation, Santa Monica

Haasnoot M, Middelkoop H, Offermans A, van Beek E, van Deursen WPA (2012) Exploring pathways for sustainable water management in river deltas in a changing environment. Clim Chang 115(3-4):795-819. doi:10.1007/s10584-012-0444-2

Haasnoot M, Kwakkel JH, Walker WE, Ter Maat J (2013) Dynamic adaptive policy pathways: a new method for crafting robust decisions for a deeply uncertain world. Glob Environ Chang 23(2):485-498. doi:10.1016/j. gloenvcha.2012.12.006

Haasnoot M, van Deursen WPA, Guillaume JHA, Kwakkel JH, van Beek E, Middelkoop H (2014) Fit for purpose? Building and evaluating a fast, integrated model for exploring water policy pathways. Environ Model Softw 60:99-120. doi:10.1016/j.envsoft.2014.05.020

Hamarat C, Kwakkel JH, Pruyt E (2013) Adaptive robust design under deep uncertainty. Technol Forecast Soc Chang 80(3):408-418. doi:10.1016/j.techfore.2012.10.004

Hillier FS, Liebermans GJ (2001) Introduction to operations research. McGraw Hill

Holling CS (1973) Resilience and stability of ecological systems. Annu Rev Ecol Syst 4:1-23

Kabat P, Beekma J (1994) Water in the unsaturated zone. In: Ritzema H (ed) Drainage principles and applications, 2nd edn. International Institute for Land Reclamation and Improvement, Wageningen

Kahan JP, Botterman M, Cave J, Robinson N, Shoob R, Thomson R, Valeri L (2004) Cyber Trust and Crime Prevention: Gaining Insight from Three Different Futures. Prepared for Foresight Directorate, Office of Science and Technology, UK

KNMI (2006) Climate Change Scenarios 2006 for the Netherlands. KNMI de Bilt, Netherlands

Knol A, Slottje P, van der Sluijs JP, Lebret E (2010) The use of expert elicitation in environmental health impact assessment: a seven step procedure. Environ Heal 9(1):19

Kwadijk JCJ, Haasnoot M, Mulder JPM, Hoogvliet MMC, Jeuken ABM, van der Krogt RAA, van Oostrom NGC, Schelfhout HA, van Velzen EH, van Waveren H, de Wit MJM (2010) Using adaptation tipping points to prepare for climate change and sea level rise: a case study in the Netherlands. Wiley Interdiscip Rev Clim Chang 1(5):729-740. doi:10.1002/wcc.64

Kwakkel JH, Walker WE, Marchau VAWJ (2010) Adaptive airport strategic planning. Eur J Transp Infrastruct Res 10(3):227-250

Kwakkel JH, Mens MJP, de Jong A, Wardekker JA, Thissen WAH, van der Sluijs JP (2011) Uncertainty Terminology. Knowledge for Climate. 30pp. http://goo.g1/H91ei

Lehner B, Döll P, Alcamo J, Henrichs T, Kaspar F (2006) Estimating the Impact of Global Change on Flood and Drought Risks in Europe: a continental integrated analysis. Clim Chang 75:273-299. doi:10.1007/s10584-006-6338-4

Lempert RJ (2002) A new decision sciences for complex systems. Proc Natl Acad Sci U S A 99:7309-7313

Lempert RJ, Popper S, Bankes S (2003) Shaping the next one hundred years: new methods for quantitative, long term policy analysis. RAND, Santa Monica

Lourenço TC, Rovisco A, Groot A, Nilsson C, Fussel HM, van Bree L, Street RB (eds) (2014a) Adapting to an uncertain climate: lessons from practice. Springer, Berlin

Lourenço TC, Rovisco A, Groot A (2014b) Making adaptation decisions under uncertainty: lessons from theory and practice. In: Lourenço TC, Rovisco A, Groot A, Nilsson C, Fussel HM, van Bree L, Street RB (eds) Adapting to an uncertain climate: lessons from practice. Springer, Berlin, pp 139-162

Malatinszky Á, Ádám S, Saláta-Falusi E, Saláta D, Penksza K (2013) Planning management adapted to climate change effects in terrestrial wetlands and grasslands'. Int J Glob Warming 5(3):311-325

Marchau VAWJ, Walker WE, Van Duin R (2009) An adaptive approach to implementing innovative urban transport solutions. Transp Policy 15:405-412

Matrosov ES, Woords AM, Harou JJ (2013a) Robust decision making and info-gap decision theory for water resource system planning. J Hydrol 494:43-58

Matrosov ES, Padula S, Harou JJ (2013b) Selecting portfolios of water supply and demand management strategies under uncertainty - contrasting economic optimisation and 'robust decision making' approaches. Water Resour Manag 27:1123-1148. doi:10.1007/s11269-012-0118-x

Maxim L, Van der Sluijs JP (2011) Quality in environmental science for policy: assessing uncertainty as a component of policy analysis. Environ Sci Pol 14(4):482-492 
McDaniel RR, Driebe DJ (eds.) (2005) Uncertainty and suprise in complex systems: questions on working the unexpected. Springer

Mens MJP, Klijn F (2015) The added value of system robustness analysis for flood risk management illustrated by a case on the IJssel River. Nat Hazards Earth Syst Sci 15:213-223. doi:10.5194/nhess-15-213-2015

Mens MJP, Klein F, De Bruijn KM, Van Beek E (2011) The meaning of system robustness for flood risk management. Environ Sci Pol 14(8):1121-1131

Mens M, Gilroy K, Wiliams D (this issue) Drought risk management under climate change uncertainty: defining critical system thresholds based on examples from the United States. Water Resources Management, this issue

Milly PCD, Betancourt J, Falkenmark M, Hirsch RM, Lettenmaier DP, Stouffer RJ (2008) Stationarity is dead: whither water management? Science 319(5863):573-574. doi:10.1126/science.1151915

Mulder HM, Veldhuizen AA (2014) AGRICOM 2.01 Manual (in Dutch). Alterra, Wageningen, the Netherlands

Offermans A (2012) Perspectives Method: towards socially robust river management. University of Maastricht, Maastricht, the Netherlands.

Oosterbaan RJ (2001) SALTMOD: description of principles. User manual and examples of application. ILRI

PBL (2013) The effects of climate change in the Netherlands: 2012. PBL Netherlands Environmental Assessment Agency, The Hague

Popper S, Griffin J, Berrebi C, Light T, Min EY (2009) Natural Gas and Israel's energy future: a strategic analysis under conditions of deep uncertainty. RAND Corporation, Santa Monica

Quade ES (1982) Analysis for public decisions. Elsevier Science Publishing Co. Inc, New York

Rijnland (2009) Water management plan Rijnland 2010-2015 (In Dutch: Waterbeheerplan 2010-2015). Leiden, the Netherlands: Waterboard of Rijnland

Snelder M, van Zuylen HJ, Immers LH (2012) A framework for robustness analysis of road networks for short term variations in supply. Transp Res A Policy Pract 46:828-842. doi:10.1016/j.tra.2012.02.007

Stelling J, Sauer U, Szallasi Z, Doyle FJ III, Doyle J (2004) Robustness of cellular functions. Cell 118:675-685. doi:10.1016/j.cell.2004.09.008

Stichting Ontwikkeling De Venen (2010) “Gebiedsconvenant Groot Wilnis - Vinkeveen 2010-2020”. Stichting Ontwikkeling De Venen, Utrecht

Swanson D, Barg S, Tyler S, Venema H, Tomar S, Bhadwal S, Nair S, Roy D, Drexhage J (2010) Seven tools for creating adaptive policies. Technol Forecast Soc Chang 77:924-939

ter Maat J, van Velzen E, van der Vat M (2013) Landelijke verkenning van effecten van maatregelpakketten voor de zoetwatervoorziening in Nederland. Deltares, Delft, the Netherlands

Urbonas BR, Roesner L (1993) Hydrologic design for urban drainage and flood control. In: Maidment DR (ed) Handbook of Hydrology. McGraw-Hill, New York, pp 28.01-28.52

Van Asselt MJA (2000) Perspectives on uncertainty and risk. Springer, Berlin

Van den Boogaard H, van Velzen E (2012) Empirical Relation between salt concentration in Rijnmond and the Rhine discharge. Deltares, Delft, The Netherlands

Van der Sluijs JP, Petersen AC, Janssen PHM, Risbey JS, Ravetz JR (2008) Exploring the quality of evidence for complex and contested policy decisions. Environ Res Lett 3:024008. doi:10.1088/1748-9326/3/2/024008 (9pp)

Van Geenhuizen M, Thissen WAH (2007) A framework for identifying and qualifying uncertainty in policy making: the case of intelligent transport systems. In: Van Geenhuizen M, Reggiani A, Rietvelt P (eds) Policy analysis of transport networks. Ashgate, Alsdershot

Van Geenhuizen M, Reggiani A, Rietveld P (2007) New trends in policymaking for transport and regional network integration. In: Van Geenhuizen M, Reggiani A, Rietvelt P (eds) Policy analysis of transport networks. Ashgate, Alsdershot

Van BL, Van der Sluijs JP (2014) Dealing with uncertainty in climate adaptation decision-making. In: Lourenço TC, Rovisco A, Groot A, Nilsson C, Fussel HM, van Bree L, Street RB (eds) Adapting to an uncertain climate: lessons from practice. Springer, Berlin, pp 17-40

Varum CA, Melo C (2010) Directions in scenario planning literature: a review of the past decades. Futures 42: 355-369

Verhoeven J, Paulissen M, Ouboter M, van der Wielen S, Wegman R, Masselink L, Goosen H (2012) Klimaateffecten op de Natura 2000 moerascorridor: quick scan in het Groene Hart. Province of ZuidHolland, The Hague

Walker B, Salt D (2006) Resilience thinking: sustaining ecosystems and people in a changing world. Island Press, Washington

Walker WE, Rahman SA, Cave J (2001) Adaptive policies, policy analysis, and policy-making. Eur J Oper Res 128(2):282-289

Walker W, Harremoes P, Rotmans J, van der Sluijs J, van Asselt M, Janssen P, Krayer von Krauss M (2003) Defining uncertainty: a conceptual basis for uncertainty management in model-based decision support. Integr Assess 4(1):5-18 
Walker B, Holling CS, Carpenter SR, Kinzig A (2004) Resilience, adaptability and transformability in socialecological systems. Ecol Soc 9(2):5-13

Walker WE, Haasnoot M, Kwakkel JH (2013) Adapt or perish: a review of planning approaches for adaptation under deep uncertainty. Sustain 2013(5):955-979. doi:10.3390/su5030955

Wardekker JA (2011) Climate change impact assessment and adaptation under uncertainty. PhD Thesis, Utrecht University. http://www.nusap.net/downloads/Wardekker_PhDdissertation_2011.pdf

Wardekker JA, de Jong A, Knoop JM, van der Sluijs JP (2010) Operationalising a resilience approach to adapting an urban delta to uncertain climate changes. Technol Forecast Soc Chang 77(6):987-998

Watt KEF, Craig PP (1986) System stability principles. Syst Res 3:191-201

Watts G, Von Christierson B, Hannaford J, Lonsdale K (2012) Testing the resilience of water supply systems to long droughts. J Hydrol 414-415(0), 255-267

Weaver CP, Lempert RJ, Brown C, Hall JW, Revell D, Sarewitz D (2013) Improving the contribution of climate model information to decision making: the value and demands of robust decision making frameworks. WIREs Clim Chang 4:39-60. doi:10.1002/wcc.202

Wise RM, Fazey I, Stafford Smith M, Park SE, Eakin HC, Archer van Garderen ERM, Campbell B (2014) Reconceptualizing adaptation to climate change as part of pathways of change and response. Glob Environ Chang. doi:10.1016/j.gloenvcha.2013.12.002 